\title{
OPEN Carbon dioxide levels in initial nests of the leaf-cutting ant Atta sexdens (Hymenoptera: Formicidae)
}

\author{
Kátia K. A. Sousa ${ }^{1}$, Roberto S. Camargo ${ }^{1 凶}$, Nadia Caldato ${ }^{1}$, Adriano P. Farias ${ }^{1}$, \\ Carlos A. O. Matos ${ }^{2}$, José C. Zanuncio ${ }^{3}$, Isabel C. L. Santos ${ }^{4} \&$ Luiz C. Forti $^{1}$
}

Claustral foundation of nests by Atta sexdens Forel (Hymenoptera: Formicidae) involves great effort by its queens, solely responsible for the cultivation of the fungus and care for her offspring at this stage. The minimum workers, after 4 months, open access to the external environment to foraging plants to cultivate the symbiotic fungus, which decomposes the plant fragments and produces gongilidea nodules as food for the individuals in the colony. Colony gas exchange and decomposition of organic matter in underground ant nests generate carbon dioxide $\left(\mathrm{CO}_{2}\right)$ emitted into the atmosphere. We described the carbon dioxide concentration in colonies in the field. The objective was to evaluate the carbon dioxide concentration in initial A. sexdens colonies, in the field, and their development. The $\mathrm{CO}_{2}$ level was also measured in 4-month-old colonies in the field, using an open respirometric system fitted with an atmospheric air inlet. The $\mathrm{CO}_{2}$ level of the respirometric container was read by introducing a tube into the nest inlet hole and the air sucked by a peristaltic pump into the $\mathrm{CO}_{2}$ meter box. The $\mathrm{CO}_{2}$ concentration in the initial colony was also measured after 4 months of age, when the offspring production (number of eggs, larvae, pupae and adult workers) stabilized. Ten perforations (15 cm deep) was carried out in the adjacent soil, without a nest of ants nearby, to determine the concentration of $\mathrm{CO}_{2}$. The composition of the nests in the field was evaluated after excavating them using a gardening shovel and they were stored in $250 \mathrm{ml}$ pots with $1 \mathrm{~cm}$ of moistened plaster at the bottom. The $\mathrm{CO}_{2}$ concentration was higher in field nest than in adjacent soil. The concentration of carbon dioxide in $A$. sexdens nests in the field is higher than in those in the soil, due to the production of $\mathrm{CO}_{2}$ by the fungus garden and colony.

Leaf-cutting ants are the main herbivores in the Americas, from the southern United States (USA) to central Argentina, with underground nests sheltering colonies with large numbers of individuals that forage fresh vegetation $^{1}$. These nests, annually, release reproductive castes that will originate new nests ${ }^{2,3}$. The foundation of claustral Atta sexdens Forel (Hymenoptera: Formicidae) nests involves a great effort by the queen as the only responsible to cultivate the fungus and caring for her offspring in this phase $e^{3,4}$.

About 3 to 4 months, after the claustral phase, average workers from initial nests clear the channel closed by the founding queen to the soil surface ${ }^{5}$. Access to the external environment allows ants to forage plant material to cultivate the symbiotic fungus Leucoagaricus gongylophorus (A. Møller) Heim) ${ }^{6}$. This fungus breaks down plant fragments and produces hyphal nodules (gongilids) that will serve as food for the individuals of the colony?

Nesting in deep soil layers facilitates the increase in the concentration of carbon dioxide $\left(\mathrm{CO}_{2}\right)^{8}$. The large volumes of this gas, produced by the ant respiration and the decomposition of organic matter, contribute to its emission from underground nests into the atmosphere ${ }^{9,10} . \mathrm{CO}_{2}$ concentrations in field nests were $0.2 \%$ in Pogonomyrmex badius (Latreille) ${ }^{11}, 1.5$ to $4.5 \%$ in A. capiguara (Gonçaves) and A. laevigata (Smith), respectively ${ }^{8}$ and $5.7 \%$ in A. vollenweideri (Forel $)^{12}$, exceeding atmospheric levels of this gas which is $0.04 \%$. The high levels of carbon dioxide in the A. vollenweideri nest, native to clayey soils, are a problem. The porosity and air permeability of these soils are $\mathrm{low}^{13}$, hindering the release of $\mathrm{CO}_{2}$ from the chambers and the supply of oxygen in the nest by diffusion with the surrounding soil. The wind-induced ventilation mechanism, according to the Bernoulli ${ }^{14}$ principle, facilitates gas exchange in A. vollenweideri nests, similar to the ventilation of the Cynomys ludovicianus ${ }^{15}$

${ }^{1}$ Departamento de Proteção Vegetal, Universidade Estadual Paulista (UNESP), Faculdade de Ciências Agronômicas, Botucatu 18603-970, Brazil. ${ }^{2}$ Campus Experimental de Itapeva, Universidade Estadual Paulista, Itapeva 18409-010, Brazil. ${ }^{3}$ Departamento de Entomologia/BIOAGRO, Universidade Federal de Viçosa, Viçosa 36570-900, Brazil. 'Laboratório de Fitossanidade (FitLab), Instituto Federal de Mato Grosso, Cáceres 78201-380, Brazil. ${ }^{\circledR}$ email: camargobotucatu@yahoo.com.br 


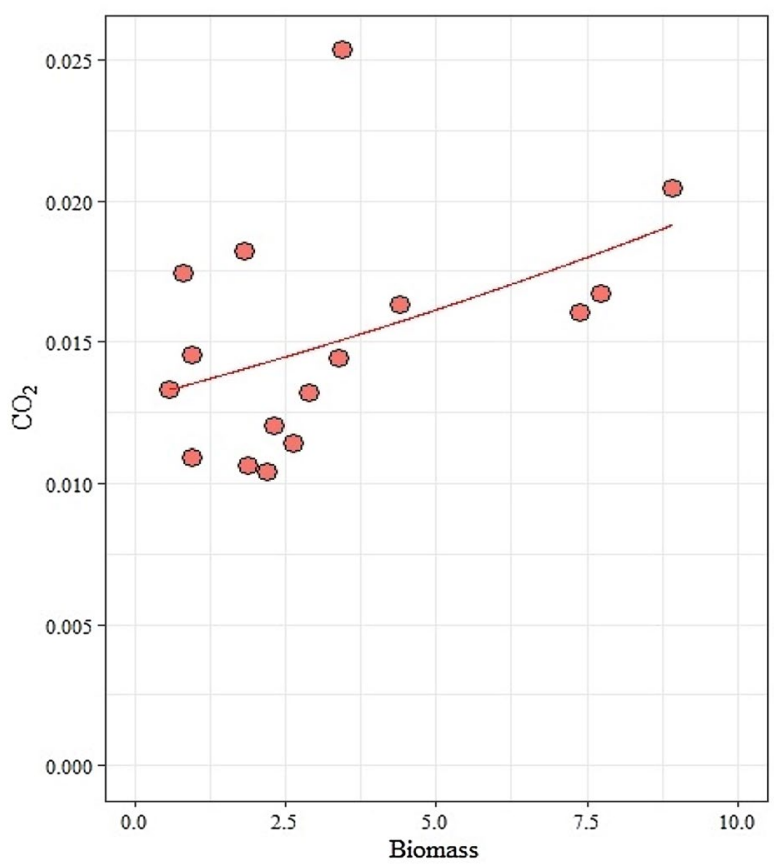

Figure 1. Relation between $\mathrm{CO}_{2}$ production and biomass of early colonies of Atta sexdens (Hymenoptera: Formicidae) in soil.

\begin{tabular}{|l|r|r|r|l|l|}
\hline Field & \multicolumn{5}{|l|}{} \\
\hline Model with logit link) & Estimate & Std. error & $\mathbf{z}$ & value $\operatorname{Pr}(>|\mathbf{z}|)$ \\
\hline \multirow{2}{*}{ Coefficients (mean: intercept model with logit link): biomass } & -4.33144 & 0.09274 & -46.705 & $<2 \mathrm{e}-16$ \\
\cline { 2 - 6 } & 0.04426 & 0.02082 & 2.126 & 0.0335 \\
\hline Phi coefficients (precision model with identity link) & 1353.5 & 480.3 & 2.818 & 0.00483 \\
\hline (Phi) &
\end{tabular}

Table 1. Summary of estimates of model coefficients $\mathrm{CO}_{2}=\mathrm{f}$ (biomass) -field. Laboratory: Log-likelihood: 155.3 on 3 Df, Pseudo R²: 0.01306; Field: Log-likelihood: 68.98 on 3 Df, Pseudo $R^{2}$ : 0.2073.

rodent burrows. These nests have up to 200 openings used as exits or entrances by the ants ${ }^{16}$ and the entrance and exit of air through them depend on their location in the soil mound. Surface wind drives air out of the central tunnels, followed by an inflow of air at the periphery. Ants build towers on the top of central openings of the nests for ventilation raising the tunnel opening and exposing them to higher surface wind speeds ${ }^{14}$. This gas exchange in adult ant nests is best studied, but this is poorly understood in early ones.

An organism's aerobic respiration releases $\mathrm{CO}_{2}$, but its rate of production expelled in early leaf-cutting ant colonies is unknown. The objective was to study the carbon dioxide concentrations in initial colonies of $A$. sexdens, in the field and their development.

\section{Results}

$\mathrm{CO}_{2}$ emission by $A$. sexdens nests (median $=1.40 \%$ ) was higher than adjacent soil (Wilcoxon rank test pval $\left.<0.05\right)$. The $\mathrm{CO}_{2}$ emission was related to fungus biomass higher (Estimated Coefficient $\left.=0.04426, \mathrm{p}<0.05\right)$ (Fig. 1).

The $\mathrm{CO}_{2}$ model $=\mathrm{f}$ (biomass) $($ Coefficient $=0.04426, \mathrm{p}<0.05)$ of $\mathrm{CO}_{2}$ emission in field colonies $($ Table 1$)$. Fungus biomass, queen mass, number of eggs and mean workers showed values of $4.70 \pm 5.05,206.73 \pm 23.45 \mathrm{mg}$, $144.33 \pm 66.31,119.61 \pm 79.34$, and 25.67 \pm 9.91 . See more details in the Supplementary Information.

\section{Discussion}

The greater $\mathrm{CO}_{2}$ emission by $A$. sexdens nests in the field than in those in the adjacent soil. Early nests of $A$. sexdens are found at a depth of around $15 \mathrm{~cm}$, where soils are one of the largest global reserves of carbon. In addition, soil fauna alters the structure of soil processes by stimulating or inhibiting the $\mathrm{CO}_{2}$ flow ${ }^{17,18}$. This may explain the greater emission of this gas by initial field nests is higher than soil matrix. However, the deepening of early Atta nests with greater numbers of chambers and tunnels increases soil manipulation and, consequently, 


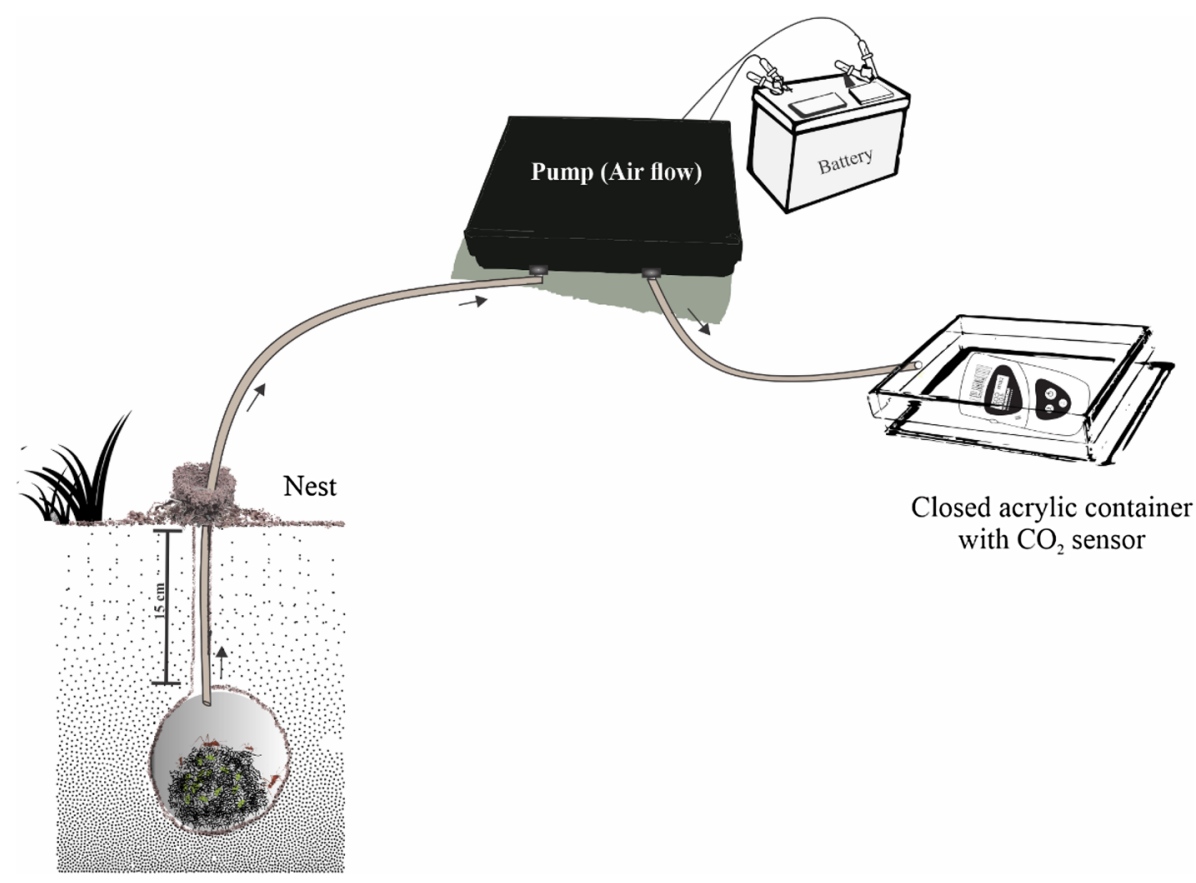

Figure 2. Scheme of the closed respirometric system used in the experiment to measure $\mathrm{CO}_{2}$ in nests of Atta sexdens (Hymenoptera: Formicidae) in field. Design created by Kátia K. A. Sousa by CorelDRAW 2019 (https:// www.coreldraw.com/br/?link=wm).

the release of gases with the amount of $\mathrm{CO}_{2}$ from adult ant nests and surrounding soils being $15 \%$ to $60 \%$ higher than those more distant ${ }^{18}$.

Differences in the $\mathrm{CO}_{2}$ model when biomass and $\mathrm{CO}_{2}$ emission in field colonies were used are due to the greater emission of this gas by the soil microbiota. Therefore, field nestsare exposed to high concentrations of carbon dioxide ${ }^{10,18,19}$. Climatic parameters such as humidity, temperature and $\mathrm{CO}_{2}$ concentration directly impact the development of the ant nest ${ }^{20}$. $\mathrm{CO}_{2}$ levels in nests of Acromyrmex lundi Guering (Hymenoptera: Formicidae) were between 1 and $3 \%$ and their workers avoided high levels of this gas ${ }^{21} . \mathrm{CO}_{2}$ values in giant nests such as $A$. vollenweideri did not exceed $28,000 \mathrm{ppm}$ due to small towers to facilitate nest ventilation and carbon dioxide removal when their levels are above $5 \%{ }^{22}$. Ants elicit specific reactions to $\mathrm{CO}_{2}$, through sensillum ampullaceum, embedded below the cuticle of the antenomer and harboring cells that receive this gas ${ }^{23,24}$.

The numbers of eggs, larvae, pupae and small and medium workers in A. sexdens colonies in field is similar to found in literature for Atta sexdens ${ }^{25}$. The factors such as temperature, humidity and plants could affect the development of fields colonies ${ }^{32}$. In the field is dement the higher energy used to excavate them and form the first chamber ${ }^{25-28}$.

The higher concentration of carbon dioxide in A. sexdens nests in the field than in the adjacent soil is due to the fact that the initial nest chamber in natural conditions produce more $\mathrm{CO}_{2}{ }^{18}$ by fungus garden and colony. In addition, Biogenic sources of $\mathrm{CO}_{2}$ can be due to decomposition of plant matter, root exudation or addition of plant residues, microbial decomposition of soil organic matter, root respiration and rhizomicrobial respiration (or fine root decomposition) $)^{29}$.

\section{Methods}

$\mathrm{CO}_{2}$ levels of field colonies. The study was carried out at Fazenda Santana near UNESP Experimental Farm Lageado, municipality of Botucatu, state of São Paulo, Brazil $\left(22^{\circ} 50^{\prime} 46^{\prime \prime} \mathrm{S}\right.$ and $\left.48^{\circ} 26^{\prime} 02^{\prime \prime} \mathrm{W}\right)$. Initial nests of A. sexdens were marked and the $\mathrm{CO}_{2}$ concentration measured in them.

An open respirometric system was built and adapted (Fig. 2) with atmospheric air inlet and the $\mathrm{CO}_{2}$ level of the respirometric container (Bacharach) measured with a fixed probe (http://www.bacharach-32.inc.com). This measurement was carried out by introducing a tube into the nest inlet hole and the air sucked by a peristaltic pump into the $\mathrm{CO}_{2}{ }^{30}$ meter box.

The nest holes were closed for $24 \mathrm{~h}$ after $\mathrm{CO}_{2}$ measurement and opened after this time when this gas were measurements again.

In addition, ten perforations ( $15 \mathrm{~cm}$ deep) was carried out in the adjacent soil, without a nest of ants nearby, to determine the concentration of $\mathrm{CO}_{2}$.

Composition of the initial colony. The composition of the initial colony was evaluated by counting the number of eggs, larvae, pupae and adult workers in 4-month-old A. sexdens nests in the field. This composition was obtained by excavating the nests using gardening shovel and storing them in $250 \mathrm{ml}$ pots with $1 \mathrm{~cm}$ of 
moistened plaster at the bottom. The offspring of each colony were counted in the laboratory under a stereomicroscope.

Statistical analysis. Statistical analyzes of proportions of $\mathrm{CO}_{2}$ production were limited between 0 and 1 with variability, commonly, according to the mean of the response, not meeting the assumptions of normal distribution of residues and homogeneous variance of standard techniques of statistical analysis. Beta regression is an easier and more flexible interpretation method than transformations (sine $\operatorname{arc}(\operatorname{root}(\mathrm{Y} / 100))$, etc.) to model proportions originating from continuous measures limited to the open interval $(0,1)$ whose most important aspects are identified by those familiar with generalized linear models (GLMs) ${ }^{31-33}$. The mean-precision parameterization, with $\mu$ (for the expected value) and $\phi$ (as a measure of 'precision', or the inverse of dispersion), is most commonly used in the context of beta regression) Maximum likelihood estimation method of $\beta$ and $\phi$ is used to best fit the data to the model. The estimated coefficients of the model are related to the linear predictor in the transformed scale:

\begin{tabular}{|l|l|l|}
\hline (Intercept) & $\mathbf{X}$ & (phi) \\
\hline-4.33144 & 0.04426 & 1353.5 \\
\hline
\end{tabular}

The estimated coefficients on the scale of the original observations must be transformed using the inverse of the link function so that the nonlinear relationship on the scale of the original observations is restored. For example, the predicted expected value when $\mathrm{X}=1$ is:

$$
\begin{gathered}
g(E[Y \mid X=1])=-4.33144+0.04426 * 1=-4.28718 \\
E[Y \mid X=1]=\frac{e^{-4.28718}}{1+e^{-4.28718}}=0.0135573
\end{gathered}
$$

The hypothesis for medians was tested with the Wilcoxon Rank Sum Test for variables without normal distribution and the means with the homoscedastic $t$ Test for variables with normal distribution. The significance level adopted in this and all other analyzes was $5 \%(\alpha=0.05)$. The analysis of standardized residuals in a contingency table was performed after the $\mathrm{X}^{2}$ independence test was performed.

Received: 27 July 2021; Accepted: 29 September 2021

Published online: 18 October 2021

\section{References}

1. Hughes, W. O. H. \& Goulson, D. The use of alarm pheromones to enhance bait harvest by grass-cutting ants. Bull. Entomol. Res. 92, 213-218 (2002).

2. Staab, M. \& Kleineidam, C. J. Initiation of swarming behavior and synchronization of mating flights in the leaf-cutting ant Atta vollenweideri Forel, 1893 (Hymenoptera: Formicidae). Myrmecol. News 19, 93-102 (2014).

3. Sales, T. A., Toledo, A. M. O. \& Lopes, J. F. S. The best of heavy queens: Influence of post-flight weight on queens' survival and productivity in Acromyrmex subterraneus (Forel, 1893) (Hymenoptera: Formicidae). Insectes Soc. 67, 383-390 (2020).

4. Camargo, R. S., Forti, L. C., Fujihara, R. T. \& Roces, F. Digging effort in leaf-cutting ant queens (Atta sexdens rubropilosa) and its effects on survival and colony growth during the claustral phase. Insectes Soc. 58, 17-22 (2011).

5. Autuori, M. Contribuição para o conhecimento da saúva (Atta spp.) (Hymenoptera: Formicidae). I. Evolução do sauveiro (Atta sexdens rubropilosa Forel, 1908). Arq. Inst. Biol. 12, 197-228 (1941).

6. Aylward, F. O. et al. Leucoagaricus gongylophorus produces diverse enzymes for the degradation of recalcitrant plant polymers in leaf-cutter ant fungus gardens. Appl. Environ. Microbiol. 79, 3770-3778 (2013).

7. Costa, A. N., Vasconcelos, H. L., Vieira-Neto, E. H. M. \& Bruna, E. M. Do herbivores exert top-down effects in Neotropical savannas? Estimates of biomass consumption by leaf-cutter ants. J. Veg. Sci. 19, 849-854 (2008).

8. Bollazzi, M., Forti, L. C. \& Roces, F. Ventilation of the giant nests of Atta leaf-cutting ants: Does underground circulating air enter the fungus chambers?. Insectes Soc. 59, 487-498 (2012).

9. Sousa-Souto, L. et al. Increased $\mathrm{CO}_{2}$ emission and organic matter decomposition by leaf-cutting ant nests in a coastal environment. Soil Biol. Biochem. 44, 21-25 (2012).

10. Hasin, S. et al. $\mathrm{CO}_{2}$ efflux from subterranean nests of ant communities in a seasonal tropical forest, Thailand. Ecol. Evol. 4, 3929-3939 (2014).

11. Tschinkel, W. R. The nest architecture of the Florida harvester ant, Pogonomyrmex badius. J. Insect Sci. 4, 21 (2004).

12. Kleineidam, C. \& Roces, F. Carbon dioxide concentrations and nest ventilation in nests of the leaf-cutting ant Atta vollenweideri. Insectes Soc. 47, 241-248 (2000).

13. Currie, J. A. Gas diffusion through soil crumbs: The effects of compaction and wetting. J. Soil Sci. 35, 1-10 (1984).

14. Kleineidam, C., Ernst, R. \& Roces, F. Wind-induced ventilation of the giant nests of the leaf-cutting ant Atta vollenweideri. Naturwissenschaften 88, 301-305 (2001).

15. Vogel, S., Ellington, C. P. \& Kilgore, D. L. Wind-induced ventilation of the burrow of the prairie-dog, Cynomys ludovicianus. J. Comp. Physiol. 85, 1-14 (1973).

16. Jonkman, J. C. M. The external and internal structure and growth of nests of the leaf-cutting ant Atta vollenweideri Forel, 1893 (Hym: Formicidae) Part II. Zeitschrift für Angew. Entomol. 89, 158-173 (1980).

17. Gutiérrez, J. L. \& Jones, C. G. Physical ecosystem engineers as agents of biogeochemical heterogeneity. Bioscience 56, 227-236 (2006).

18. Fernandez-Bou, A. S. et al. The role of the ecosystem engineer, the leaf-cutter ant Atta cephalotes, on soil $\mathrm{CO}_{2}$ dynamics in a wet tropical rainforest. J. Geophys. Res. Biogeosciences 124, 260-273 (2019).

19. Moitinho, M. R. et al. Does fresh farmyard manure introduce surviving microbes into soil or activate soil-borne microbiota? J. Environ. Manag. 11, 1-15 (2021).

20. Roces, F. Variable thermal sensitivity as output of a circadian clock controlling the bimodal rhythm of temperature choice in the ant Camponotus mus. J. Comp. Physiol. A 177, 637-643 (1995). 
21. Römer, D., Bollazzi, M. \& Roces, F. Carbon dioxide sensing in an obligate insect-fungus symbiosis: $\mathrm{CO}_{2}$ preferences of leaf-cutting ants to rear their mutualistic fungus. PLoS ONE 12, e0174597 (2017).

22. Halboth, F. \& Roces, F. The construction of ventilation turrets in Atta vollenweideri leaf-cutting ants: Carbon dioxide levels in the nest tunnels, but not airflow or air humidity, influence turret structure. PLoS ONE 12, e0188162 (2017).

23. Kleineidam, C. \& Tautz, J. Perception of carbon dioxide and other "air-condition" parameters in the leaf cutting ant Atta cephalotes. Naturwissenschaften 83, 566-568 (1996).

24. Kleineidam, C., Romani, R., Tautz, J. \& Isidoro, N. Ultrastructure and physiology of the $\mathrm{CO}_{2}$ sensitive sensillum ampullaceum in the leaf-cutting ant Atta sexdens. Arthropod Struct. Dev. 29, 43-55 (2000)

25. Camargo, R. S. \& Forti, L. C. Queen lipid content and nest growth in the leaf cutting ant (Atta sexdens rubropilosa) (Hymenoptera: Formicidae). J. Nat. Hist. 47, 65-73 (2013).

26. Seal, J. N. Scaling of body weight and fat content in fungus-gardening ant queens: Does this explain why leaf-cutting ants found claustrally?. Insectes Soc. 56, 135-141 (2009).

27. Camargo, R. D. S., Fonseca, J. A., Lopes, J. F. S. \& Forti, L. C. Influência do ambiente no desenvolvimento de colônias iniciais de formigas cortadeiras (Atta sexdens rubropilosa). Ciência Rural 43, 1375-1380 (2013).

28. Silva, E. J., da Silva Camargo, R. \& Forti, L. C. Flight and digging effort in leaf-cutting ant males and gynes. Sociobiology 62, 334-339 (2015).

29. Kuzyakov, Y. Sources of $\mathrm{CO}_{2}$ efflux from soil and review of partitioning methods. Soil Biol. Biochem. 38, 425-448 (2006).

30. Camargo, R. S., Silva, E. J., Forti, L. C. \& Matos, C. A. O. Initial development and production of $\mathrm{CO}_{2}$ in colonies of the leaf-cutting ant Atta sexdens during the claustral foundation. Sociobiology 63, 720-723 (2016).

31. Cribari-Neto, F. \& Zeileis, A. Beta regression in R. J. Stat. Softw. 34, 1-24 (2010).

32. Ferrari, S. \& Cribari-Neto, F. Beta regression for modelling rates and proportions. J. Appl. Stat. 31, 799-815 (2004).

33. Smithson, M. \& Verkuilen, J. A better lemon squeezer? Maximum-likelihood regression with beta-distributed dependent variables. Psychol. Methods 11, 54 (2006).

\section{Acknowledgements}

To "Coordenação de Aperfeiçoamento de Pessoal de Nível Superior-Brazil (CAPES-Finance Code 001)" and "Programa Cooperativo sobre Proteção Florestal (PROTEF) do Instituto de Pesquisas e Estudos Florestais (IPEF)". Luiz Carlos Forti was the recipient of a grant from Conselho Nacional de Desenvolvimento Científico e Tecnológico (CNPq) (Grant 301-938/2017-2).

\section{Author contributions}

R.S.C., L.C.F and N.C. conceived the experiment(s), K.K.A.S., R.S.C., N.C. and A.P.F. conducted the experiment(s), C.A.O.M., I.C.L.S., J.C.Z., R.S.C. and K.K.A.S. analysed the results and wrote the manuscript. All authors reviewed the manuscript.

\section{Competing interests}

The authors declare no competing interests.

\section{Additional information}

Supplementary Information The online version contains supplementary material available at https://doi.org/ 10.1038/s41598-021-00099-8.

Correspondence and requests for materials should be addressed to R.S.C.

Reprints and permissions information is available at www.nature.com/reprints.

Publisher's note Springer Nature remains neutral with regard to jurisdictional claims in published maps and institutional affiliations.

(c) (i) Open Access This article is licensed under a Creative Commons Attribution 4.0 International

License, which permits use, sharing, adaptation, distribution and reproduction in any medium or format, as long as you give appropriate credit to the original author(s) and the source, provide a link to the Creative Commons licence, and indicate if changes were made. The images or other third party material in this article are included in the article's Creative Commons licence, unless indicated otherwise in a credit line to the material. If material is not included in the article's Creative Commons licence and your intended use is not permitted by statutory regulation or exceeds the permitted use, you will need to obtain permission directly from the copyright holder. To view a copy of this licence, visit http://creativecommons.org/licenses/by/4.0/.

(c) The Author(s) 2021 